\title{
Heart block with infected cardiac rheumatoid granulomas
}

\author{
P. J. Gallagher and G. A. Gresham \\ From the Department of Morbid Anatomy and Histology, \\ fohn Bonnett Clinical Laboratories, Addenbrooke's Hospital, Cambridge
}

The association of heart block and an infected rheumatoid granuloma in the region of the atrioventricular node is reported. A causative relationship is probable.

While the existence of a specific rheumatoid heart disease remains debatable (Hart, 1969), the occurrence of cardiac granulomas resembling those seen in rheumatoid disease is not uncommon (Sinclair and Cruickshank, 1956). In the patient described below the involvement of the atrioventricular node by such a lesion provides a novel morphological explanation for heart block.

\section{Case report}

A 65-year-old housewife with an 8-year history of active rheumatoid disease developed complete heart block in March 1970. The presenting history of faintness and dizzy spells spanned only a few days. Typical electrocardiographic changes were present with an idioventricular rate of 38 beats a minute. A fixed-rate Devices pacemaker was inserted and functioned satisfactorily for 9 months. Some competition between the patient's sinus rhythm and the pacemaker was noted over this period but at first propranolol (up to $80 \mathrm{mg}$ t.d.s.) and digoxin $(0.25 \mathrm{mg}$ daily) produced satisfactory suppression. Persistence of competition and increasing peripheral oedema necessitated replacement of the original unit by a 'demand' Devices pacemaker.

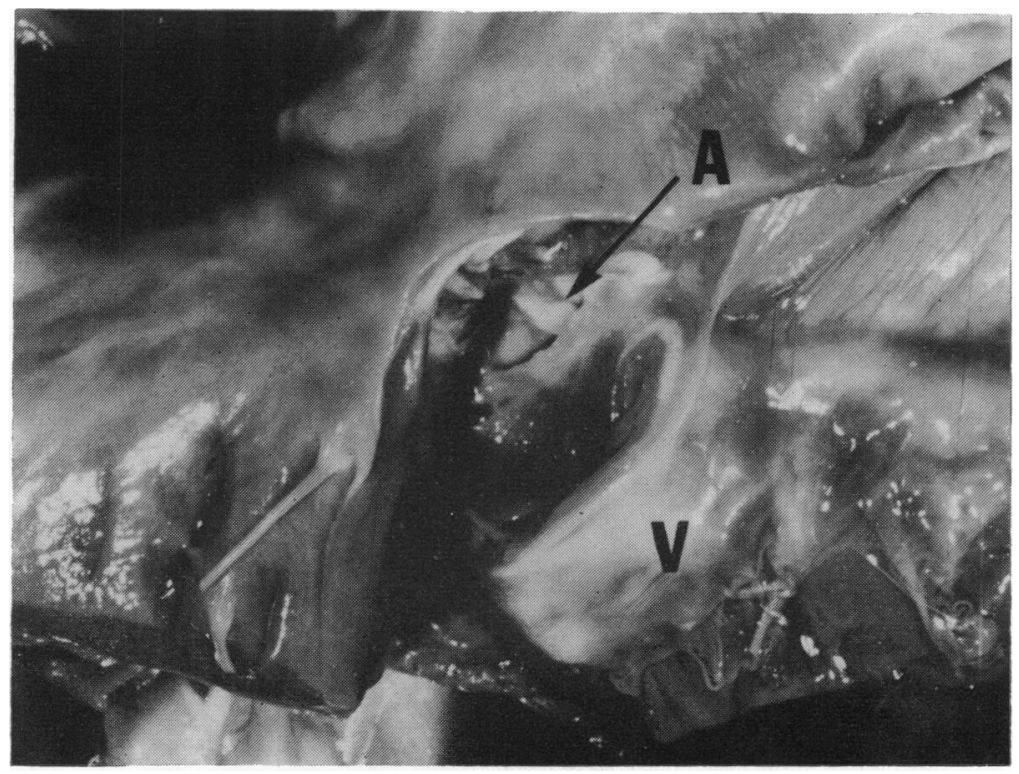

FIG. I Septal abscess. A: abscess; V: medial cusp of tricuspid valve. 


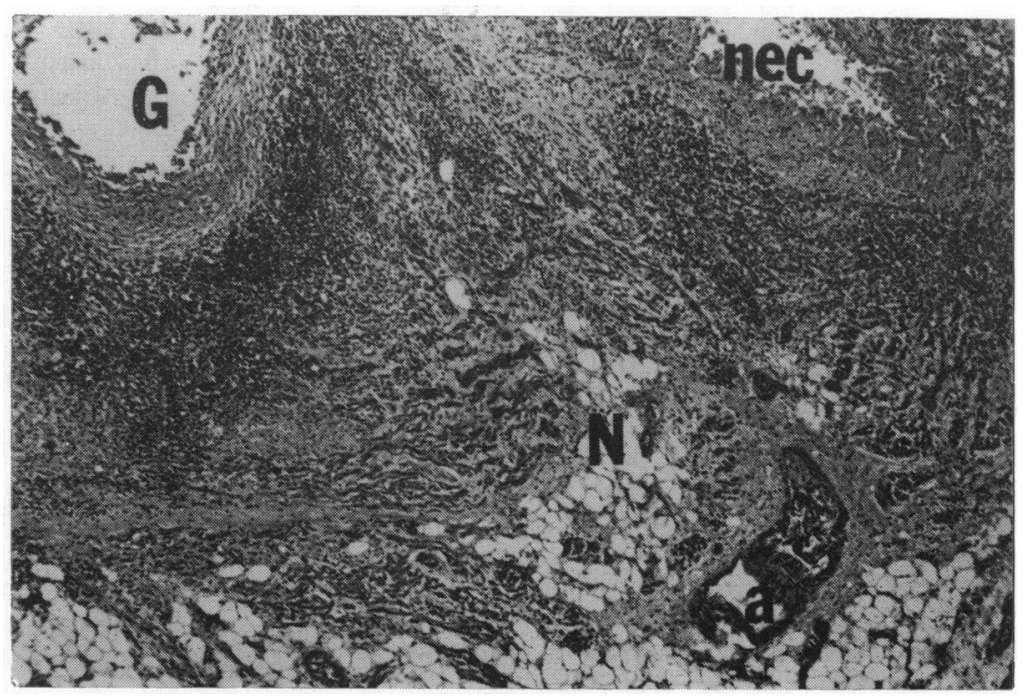

FIG. 2 Septal abscess $(\times 320)$. Nodal fibres lie just to the left of $N$, in characteristic association with adipose tissue. The branching vessel (a) may be the nodal artery. The centre of the granuloma is at $G$ and there is extensive necrosis (nec).

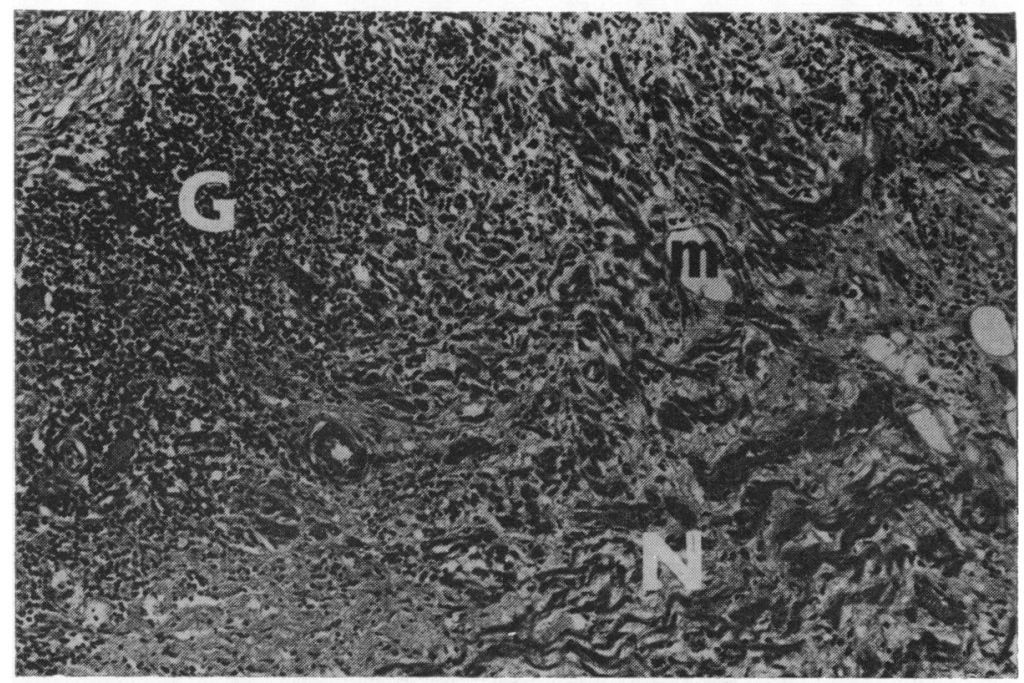

FIG. 3 Atrioventricular node $(\times 800)$. Wavy thin nodal fibres $(N)$ contrast with larger normal fibres $(M)$. The close relation of the node to the granuloma $(G)$ can be seen. 
In June 1971, after a 3-week period of epigastric discomfort, a sudden severe upper abdominal pain precipitated admission under a surgical firm. In the short period in hospital before death the blood pressure fell to $70 / 50 \mathrm{mmHg}$ and the pulse rate and central venous pressure rose. Atrial flutter and a 2:I heart block was detected in the electrocardiogram. Heart sounds, soft but audible on admission, became almost imperceptible some hours before death. Intra-abdominal disease was thought by the surgeons to have led to death.

At necropsy the pericardium contained $700 \mathrm{ml}$ purulent yellow fluid. Two cardiac abscesses were identified: one in the pericardial sac at the root of the aorta and another $(\mathrm{I} \cdot 3 \times 0.4 \times 0.4 \mathrm{~cm})$ in the uppermost part of the interventricular septum. The latter was palpable behind the medial cusp of the tricuspid valve, through which it was exposed (Fig. I). Of the coronary arteries, only the anterior descending branch of the left showed significant atherosclerosis. No abnormal fibrous tissue replacement of the myocardium was detected. Detailed examination of other organs revealed no contributory abnormalities.

Histological blocks were taken through the abscess cavities, the ventricular septum, and representative areas of the remaining chambers. Both abscesses had the histological characteristics of rheumatoid granulomata and in addition contained moderate numbers of Gramnegative bacilli. A pure growth of a non-lactose fermenting Esch. coli was obtained from a necropsy culture of the septal lesion and a similar organism was found in the spleen. A mixed pattern of growth was obtained from the pericardial fluid, suggesting postmortem contamination. In a section of one of the blocks of the septal abscess, fibres of the atrioventricular node were identified contiguous with the granuloma (Fig. 2). The nodal fibres were well preserved histologically (Fig. 3) and nearby strands of collagenous tissue were shown with appropriate staining.

\section{Discussion}

Pathological processes affecting the atrioventricular node are well recognized in association with heart block. A recent series (Davies, 1967) details amyloidosis, transfusional siderosis, diffuse fibrosis, and focal necrosis in acute myocardial infarction as aetiological factors. We feel that our histological evidence strongly suggests that this patient's heart block can be ascribed to invasion of the atrioventricular node by the rheumatoid granuloma. The duration of the heart block (15 months) is quite consistent with such an indolent lesion and its variable pattern may be related to the preservation of some nodal fibres.

The frequency of infections in rheumatoid arthritis is well recognized (Hart, 1970) and in our experience they are often undiagnosed. In this instance it was an acute purulent pericarditis that was mistaken for an intra-abdominal surgical catastrophe.

\section{References}

Davies, M. J. (1967). A histological study of the conduction system in complete heart block. Fournal of Pathology and Bacteriology, 94, 351.

Hart, F. D. (1969). Rheumatoid arthritis: extra-articular manifestations. British Medical fournal, 3, 131.

Hart, F. D. (1970). Rheumatoid arthritis: extra-articular manifestations. Part II. British Medical fournal, 2, 747.

Sinclair, R. J. G., and Cruickshank, B. (1956). A clinical and pathological study of sixteen cases of rheumatoid arthritis with extensive visceral involvement. Quarterly fournal of Medicine, 25, 313.

Requests for reprints to Dr. G. A. Gresham, Addenbrook's Hospital, Trumpington, Cambridge. 